\title{
Autoantibodies in liver disease: important clues for the diagnosis, disease activity and prognosis
}

\author{
Takashi Himoto $\cdot$ Mikio Nishioka
}

Received: 27 November 2012/ Accepted: 18 January 2013/Published online: 22 February 2013

(C) Springer-Verlag Italia 2013

\begin{abstract}
It has been well established that numerous kinds of autoantibodies have been detected in liver disease. Some kinds of autoantibodies may be helpful in the diagnosis of autoimmune liver diseases including autoimmune hepatitis, primary biliary cirrhosis or primary sclerosing cholangitis. However, these autoantibodies are present even in sera of patients with viral hepatitis, drug-induced hepatitis, alcoholic liver disease, non-alcoholic fatty liver disease and hepatocelluar carcinoma as well as in sera of patients with autoimmune liver diseases. Other kinds of autoantibodies are recognized as predictive hallmarks for disease activity or prognosis in liver diseases. On the other hand, treatment with interferon initiates the production of several types of autoantibodies in patients with chronic hepatitis $\mathrm{C}$ virus infection. Some of autoantibodies induced by interferon may postulate the treatment outcome in those patients. Recent studies also revealed the close correlation between oxidative stress and the production of autoantibodies in liver diseases. This article primarily reviews the recent advances of autoantibodies in the liver diseases and discusses the clinical significance of these autoantibodies.
\end{abstract}

Keywords Autoantibodies - Autoimmune liver diseases . Diagnosis $\cdot$ Disease activity $\cdot$ Prognosis

\footnotetext{
T. Himoto

Department of Integrated Medicine, Kagawa University

School of Medicine, Kagawa 761-0793, Japan

T. Himoto $(\square) \cdot$ M. Nishioka

Department of Gastroenterology and Neurology, Kagawa University School of Medicine, Kagawa 761-0793, Japan

e-mail: thimoto@med.kagawa-u.ac.jp
}

\section{Introduction}

Autoantibodies are produced by humoral immune responses against self-cellular proteins and nucleic acids [1], and have been well established as serological hallmarks of autoimmune disease. Numerous autoantibodies have been isolated from sera of patients with liver diseases. These autoantibodies have often clinical values for the diagnosis, disease activity and/or prognosis. Such autoantigens are primarily engaged in essential cellular functions including DNA replication, DNA transcription, and RNA processing [2].

Autoantibodies in the field of liver disease are mainly classified into two entities: (1) non-organ specific autoantibodies including antinuclear antibodies (ANA), smooth muscle antibodies (SMA), antimitochondrial antibodies (AMA), and antibodies to liver kidney microsome type-1 (LKM-1), (2) liver-specific autoantibodies such as antibodies to soluble liver antigen (SLA) and antibodies to asialoglycoprotein receptor (ASGPR) [3]. The presence of these autoantibodies are essential in the process of diagnosing autoimmune liver diseases, including autoimmune hepatitis (AIH), primary biliary cirrhosis (PBC) or primary sclerosing cholangitis (PSC). However, some of these autoantibodies are occasionally detected even in the sera of patients with liver disease other than autoimmune liver diseases [3-6]. Recent advances in proteomic or microarray analyses have led to the identification of novel autoantigens from patients with $\mathrm{AIH}[7,8]$ or hepatocellular carcinoma (HCC) [9], although the clinical relevance of antoantibodies to the novel autoantigens remains obscure.

In addition, the relationship between insulin resistance in obese human and several types of autoantibodies has been shown. For example, thyroid autoantibodies are frequently found in obese females [10]. Another study 
revealed that insulin resistance was closely related to distinct profiles of $\operatorname{IgG}$ in an experimental animal model of obesity [11].

Novel concepts have also been proposed in autoimmune liver diseases. IgG4-associated $\mathrm{AIH}$, a new entity which is characterized by a higher IgG4 concentration and IgG4-bearing plasma cells, was proposed by Umemura et al. [12]. However, no peculiar autoantibodies associated with the elevation of IgG4 levels have, thus, far been found among the patients with IgG4associated AIH. Th17-cells, which arise in the presence of transforming growth factor-beta (TGF- $\beta$ ) and interleukin-6 (IL-6), play important roles in the pathogenesis of autoimmune diseases. However, the putative mechanism by which Th17 cells contribute to the production of autoantibodies remains unclear in autoimmune liver disease [13]. Moreover, Czaja and colleagues [14] proposed a new concept, "autoantibody-negative autoimmune hepatitis". However, most of patients with autoantibodynegative AIH may have unknown autoantibodies that are still undiscovered or have delayed appearance of the conventional autoantibodies.

This review mainly focuses on the current interpretation and potential application of autoantibodies in liver diseases.

\section{Autoantibodies in liver diseases}

Table 1 summarizes the numerous types of autoantibodies in the field of liver disease. These autoantibodies are detected in the sera of patients with viral hepatitis, alcoholic liver disease, non-alcoholic fatty liver disease (NAFLD), drug-induced hepatitis, and HCC as well as autoimmune liver diseases. These autoantibodies are rarely present even in the normal healthy control. Some autoantibodies are essential to the diagnosis [3-6], while others have clinical significance for judging the prognosis $[15,16]$.

\section{Mechanisms of autoantibody production}

Impaired regulatory T cells and NKT cells

Regulatory $\mathrm{T}$ cells (Treg) are considered to serve as the maintenance of immunological self-tolerance and prevention of autoimmunity. On the other hand, natural killer $\mathrm{T}$ (NKT) cells, a T cell subset that co-expresses the NK cell marker, regulate immune system by inducing apoptosis of altered hepatocytes. A decrease in the number and function of Treg [17, 18] and NKT cells [19] eventually leads to the facilitation of type 2 cytokine (IL-4, IL-10) responses which expand the clone of plasma cells, resulting in the promotion of autoantibody production [20]. These phenomena have already been confirmed in patients with AIH and $\mathrm{PBC}$.

\section{Elevated BAFF levels}

B-lymphocyte activating factor (BAFF), a member of the tumor necrosis factor superfamily, is mainly secreted from myeloid cells (macrophages, monocytes, and dendritic cells) and plays crucial roles in the maturation and survival of B cells. Therefore, the elevation of serum BAFF levels contributes to the polyclonal activation of B cells. Serum BAFF levels were closely related to the titers of AMA in patients with PBC [21] and antibodies to cardiolipin in patients with hepatitis $\mathrm{C}$ virus (HCV) infection [22].

\section{Molecular mimicry}

Molecular mimicry between autoantigens and infectious agents including several kinds of bacteria and viruses may occasionally trigger the autoantibody production. The HCV polyprotein has a molecular mimicry with cytochrome p450 2D6 (CYP2D6), a target antigen of antibodies to LKM-1, and the cross-reactivity initiates the emergence of anti-LKM-1 in patients with chronic HCV infection [23].

Molecular mimicry and immunological cross-reactivity between Escherichia coli (E.coli) and human PDC-E2, a major target antigen of AMA, result in the production of AMA in patients with PBC [24]. Exposure to chemical xenobiotics including 2-nonynoic acid can also trigger the production of AMA in PBC patients [25].

Innate immunity

Recent studies reveal that the hyper-responsiveness of innate immunity is frequently involved in the pathogenesis of PBC. Exposure to $\mathrm{CpG}$, a ligand to TLR9, resulted in B cell activation and the subsequent facilitation of AMA production [26].

Genetic factors

Genetic predisposition of the host may account for the production of autoantibodies in liver diseases. For example, SMA and high titers of ANA were associated with human leukocyte antigen (HLA)-DR4 in patients with type $1 \mathrm{AIH}$ [27]. We also revealed that antibodies to doublestranded DNA (ds-DNA) were also related to HLA-DR4 in ANA-positive patients with AIH [28]. 
Table 1 Clinical significance of autoantibodies in liver disease

\begin{tabular}{|c|c|c|c|}
\hline Autoantibodies & Molecular target & Associated liver diseases & Clinical significance \\
\hline \multirow[t]{5}{*}{ ANA } & Histone & Type 1 AIH, PBC & $\mathrm{H} 3$-predominant in type $1 \mathrm{AIH}$ \\
\hline & Chromatin & Type 1 AIH & Higher IgG levels \\
\hline & dsDNA & Type 1 AIH & Diseases activity, unfavorable prognosis \\
\hline & Centromere & PBC, type $1 \mathrm{AIH}, \mathrm{HCV}$ (rare) & $\begin{array}{l}\text { Complementry marker for } \mathrm{PBC} \text { in } \\
\text { AMA-negative case }\end{array}$ \\
\hline & hnRNP & Type 1 AIH & Specific to type $1 \mathrm{AIH}$ \\
\hline \multirow[t]{5}{*}{ SMA } & Actin & Type 1 AIH & $\begin{array}{l}\text { Diagnostic marker for type } 1 \mathrm{AIH}, \\
\text { unfavorable prognosis }\end{array}$ \\
\hline & Myosin & $\mathrm{HCV}$ & \\
\hline & Vimentin & & \\
\hline & Tublin & Alcohlic liver diseases & \\
\hline & Desmin & & \\
\hline \multirow[t]{2}{*}{ Anti-LKM1 } & CYP2D6 & Type 2 AIH, HCV & Diagnostic marker for type $2 \mathrm{AIH}$ \\
\hline & CYP2A6 & $\mathrm{HCV}$ (rare) & \\
\hline Anti-LKM2 & CYP2C9 & Tienilic acid-included hepatitis & \\
\hline Anti-LKM3 & UGT1A2 & HDV, HCV (rare) & \\
\hline Anti-LC1 & $\begin{array}{l}\text { Formiminotransferase } \\
\text { cyclodeaminase }\end{array}$ & Type 2 AIH, HCV & Diagnostic marker for type $2 \mathrm{AIH}$ \\
\hline Anti-SLA/LP & $\begin{array}{l}\text { UGA supressor tRNA-associated } \\
\text { protien }\end{array}$ & Type 1 AIH, HCV (rare) & $\begin{array}{l}\text { Disease activity, relapse after drug } \\
\text { withdrawal }\end{array}$ \\
\hline \multirow[t]{4}{*}{ pANCA } & Actin & Type 1 AIH & \\
\hline & HMG & Type 1 AIH & \\
\hline & Lactoferrin & Type 1 AIH, PBC, PSC, HCV & \\
\hline & $\begin{array}{l}50 \mathrm{kD} \text { myeloid-specific nuclear } \\
\text { envelope protien }\end{array}$ & PSC, type 1 AIH & \\
\hline Anti-ASGPR & Asialoglycoprotein receptor & $\begin{array}{l}\text { Type } 1 \mathrm{AIH}, \mathrm{PBC}, \mathrm{HBV}, \mathrm{HCV}, \mathrm{HDV} \text { drug- } \\
\text { induced hepatitis }\end{array}$ & $\begin{array}{l}\text { Diseases activity, relapse after drug } \\
\text { withdrawal }\end{array}$ \\
\hline \multirow[t]{2}{*}{ AMA } & PDC-E2 & PBC, AIH (rare), HCV (rare) & Diagnostic marker for PBC \\
\hline & BCOAD-E2, OGDC-E2 & $\mathrm{PBC}$ & Specific to PBC \\
\hline tTGA & Tissue transglutaminase & Celiac disease & Disease activity \\
\hline ASCA & Saccharomyces cerevisiae & Type 1 AIH, PBC, PSC, celiac disease & Correlation with IgA levels \\
\hline Anti-GST & Glutathione S-transferase & Type $1 \mathrm{AIH}$ & Disease activity, unfavorable prognosis \\
\hline Anti-GW/PB & GW/PB & PBC & \\
\hline Anti-CRP & CRP & $\mathrm{HCV}$ & $\begin{array}{l}\text { Predictive marker for concurrent mixed } \\
\text { cryoglobulinemia }\end{array}$ \\
\hline
\end{tabular}

\section{Diagnostic and prognostic values of autoantibodies in liver disease}

\section{Antinuclear antibodies (ANA)}

\section{Diagnostic value}

The presence of ANA and/or smooth muscle antibodies (SMA) requires the diagnosis of type $1 \mathrm{AIH}$, the classical type of AIH [29]. However, ANA is also present in the sera of patients with other autoimmune liver diseases including PBC and PSC, and even in the sera of patients with viral hepatitis, drug-induced hepatitis, NAFLD, alcoholic liver disease, and HCC [3-6].
ANA is usually assessed by the indirect immunofluorescent (IIF) method using HEp-2 cells. The target antigens of ANA in type 1 AIH contain a heterogeneous group of structures, such as nuclear DNA, nuclear structural and functional proteins or centromeres [30]: different immunofluorescent staining types including homogeneous, speckled, nucleolar and discrete speckled patterns are shown on HEp-2 cells [31]. We previously revealed that the most common immunofluorescent staining type in patients with AIH type 1 was a homogeneous pattern [31]. Notably, heterogeneous nuclear ribonucleoprotein (hnRNP) A2/B1, which belongs to RNA-binding protein, was recently identified by Ballot's group as one of the liver-specific nuclear antigens in type $1 \mathrm{AIH}$ [32]. hnRNP A2/B1 is 
largely engaged in the maturation of mRNA precursor and in the transport of mRNA to the cytosolic compartment.

On the other hand, several kinds of ANA specific for PBC have been well studied. These PBC-specific ANA can be mainly divided into two groups by the immunofluorescent pattern on HEp-2 cells: the rim-like membranous pattern and the multiple nuclear dots pattern [33]. ANA showing the rim-like pattern on HEp-2 cells are largely directed against to nuclear pore complexes (gp210 [34] and nucleoporin p62 [35]), while ANA exhibiting multiple nuclear dot pattern are directed against to nuclear body proteins including sp100 [36], promyelocytic leukemia (PML) protein [37], small ubiquitin-related modifiers (SUMO) [38], and more recently sp140 [39] (Table 2). The specificity of anti-gp210 was estimated for more than $96 \%$, although the prevalence of the antibody ranged from 9.4 to $41.2 \%$ of patients with PBC [40].

ANA were present in approximately $10-40 \%$ of patients with HCV-related chronic liver disease (CLD) [41-44]. Molecular mimicry between viral and self antigens may trigger the immunological cross-reaction. Gregirio and colleagues documented molecular mimicry between $\mathrm{HCV}$ polyprotein and matrin, histone $\mathrm{H} 2 \mathrm{~A}$ or replication protein $\mathrm{A}$ [45].

\section{Clinical significance in predicting disease activity and/or concurrent autoimmune diseases}

Antibodies to chromatin are directed against the complex of histones and DNA. These antibodies were found in 20-50 \% of patients with type 1 AIH $[46,47]$. AIH patients with anti-chromatin had a biochemical characteristic of higher IgG levels [46, 47].

Antibodies to histone were present in $35 \%$ of ANApositive patients with $\mathrm{AIH}$ [48]. IgG type antibodies to histone in sera of patients with AIH showed dominant reactivity against $\mathrm{H} 3$ among individual histones $(\mathrm{H} 1, \mathrm{H} 2 \mathrm{~A}$, $\mathrm{H} 2 \mathrm{~B}, \mathrm{H} 3$ and $\mathrm{H} 4$ ), while the reactivity in patients with $\mathrm{PBC}$ was predominant against H1 [49]. Unfortunately, anti-histone were not associated with disease activity in patients with AIH. However, the titer of anti-H3 was decreased by the treatment with corticosteroid in proportion to the serum ALT level in each individual [49].
In contrast, antibodies to dsDNA were detected in less than half of patients with type 1 AIH $[28,50]$. The emergence of anti-dsDNA may reflect higher IgG levels and more frequent failures to the treatment with corticosteroid in patients with AIH. On the other hand, Muratori and colleagues [51] demonstrated that concomitant anti-dsDNA and AMA were the serological profile of AIH/PBC overlap syndrome.

Recently, we revealed that anticentromere antibodies were present in eight (17\%) of 47 patients with type $1 \mathrm{AIH}$ [52]. Those patients with anticentromere antibodies had clinical characteristics of lower serum IgG levels than those with other immunofluorescent staining patterns of ANA, although no significant difference in histological activities between the two groups was found.

ANAs specific to PBC can conveniently predict the disease activity or a concurrent infection. Antibodies to gp210 were associated with severe interface hepatitis lobular inflammation [53]. The frequency of anti-sp-100 in patients with $\mathrm{PBC}$ and recurrent urinary tract infection was higher than that in patients with $\mathrm{PBC}$ without urinary tract infection [54]. It is of interest that Rigopoulou and colleagues [55] revealed that the IgG3 isotype of ANA specific to $\mathrm{PBC}$ was associated with more severe biochemical and histological activities.

The detection of antibodies to SS-A/Ro implied concurrent Sicca syndrome in patients with PBC [56, 57], while anticentromere antibody was associated with CREST syndrome in those patients [57, 58]. Moreover, antibodies to SS-A/Ro52 were predictive markers for a more advanced histological stage at the diagnosis of PBC [57].

ANA status also affected the disease severity in patients with HCV-related CLD. Those patients with ANA frequently had more advanced fibrosis and necroinflammation in the liver than those without ANA [43, 59]. Those patients with ANA had biochemical and immunological characteristics of higher serum alkaline phosphatase and $\gamma$ GTP levels, indicating bile duct lesions, as well as ALT and IgG levels [42, 60], and the most commonly speckled pattern on HEp-2 cells by the IIF method [60]. These clinical characteristics were independent of $\mathrm{HCV}$ genotypes and loads of HCV-RNA [59, 61].
Table 2 Prognostic values of PBC-specific ANA

\begin{tabular}{|c|c|c|}
\hline $\begin{array}{l}\text { Immunofluorescent } \\
\text { pattern }\end{array}$ & Nuclear antigens & Clinical significance \\
\hline Rim-like/membranous & $\begin{array}{l}\text { gp210 nucleoporin/p62 lamin B } \\
\text { receptor }\end{array}$ & $\begin{array}{l}\text { Progression to liver failure advanced liver } \\
\text { stage }\end{array}$ \\
\hline \multirow[t]{3}{*}{ Multiple nuclear dots } & Sp100 & Recurrent urinary tract infection \\
\hline & Sp140 & Coexistence with anti-Sp100 \\
\hline & PML & Coexistence with anti-Sp100 \\
\hline Discrete speckled & CENP-B & Progression to portal hypertension \\
\hline
\end{tabular}


Recent studies have revealed that around approximately 20-30\% of patients with non-alcoholic fatty liver disease (NAFLD) or non-alcoholic steatohepatitis (NASH) also had ANA [62-64]. One of the studies showed that high titers of ANA, not SMA, in NAFLD were tightly associated with insulin resistance [62]. In general, patients with NASH, who were seropositive for ANA also seemed to have more severe fibrosis and necroinflammation in the liver than those with NASH, who were seronegative for ANA [63].

\section{Prognostic value}

The subtype of ANA detected in the sera of patients with PBC exhibits a variety of prognoses in PBC. Antibodies to gp210 might be a predictive factor for the progression to liver failure [65].

The emergence of antibodies to Ro52 alone or in combination with antibodies to SLA in patients with type 1 AIH represented an unfavorable prognosis [66].

Antibodies to chromatin are also recognized as a candidate forecasting relapse after withdrawal of the treatment in patients with AIH [47].

On the other hand, PBC patients with anticentromere antibodies were previously considered to have mild liver injury and show a favorable prognosis [67]. However, recent articles revealed that anticentromere antibodies have been the risk factors for the development of portal hypertension in those patients [65]. Moreover, we previously implied that patients with HCV-related CLD seropositive for anticentromere antibodies more frequently progressed to HCC [68].

\section{Smooth muscle antibodies (SMA)}

\section{Diagnostic value}

SMA is directed against structures of the cytoskeleton such as microfilaments (actin and myosin), intermediate filaments (vimentin and desmin), and microtubules (tubulin) [69]. In type 1 AIH, SMA are predominantly directed against filamentous (polymerized) actin (F-actin) [70]. Therefore, antibodies to F-actin (anti-F-actin) are serological hallmarks specific to type 1 AIH [71]. The analysis of anti-F-actin is usually performed by an indirect IIF method using fibroblasts, which have peculiar stress fibers [72]. Phalloidin-treated rat hepatocytes have been also used as substrates for IIF, which were stained with a polygonal pattern on the hepatocytes [73]. However, the assay for anti-F-actin gives controversial results because of a conformational change of actin epitopes [72]. Moreover, the IIF procedure for detecting anti-F-actin is somewhat complicated, and interpretation of the results depends on the operator's experience. Recently, a commercially available kit using the VSM 47 cells line, which is obtained from the thoracic aorta of rat embryo, as a novel substrate enabled us to analyze anti-F-actin more easily [74].

Other methods for the detection of anti-F-actin include immunoprecipitation, ELISA, protein binding assay, and passive hemoagglutination and immunoblot techniques [71, 73]. The trouble is that a gold standard method for anti-F-actin have not yet been established. However, a commercially available ELISA kit for detecting antibodies against F-actin was recently developed. The detection of anti-F-actin using this kit had almost the same specificity but higher sensitivity in the diagnosis of type $1 \mathrm{AIH}$, compared with the IIF technique [75, 76].

Anti-F-actin are likely to recognize a specific epitope corresponding to the $\alpha$-actinin-binding domain. Gueguen and colleagues emphasized the importance of analyzing both anti-actin and anti- $\alpha$-actinin antibodies in patients with type $1 \mathrm{AIH}$ [77]. One-third of sera with type $1 \mathrm{AIH}$ reacted simultaneously with anti-F-actin and anti- $\alpha$-actinin. Moreover, antibodies to $\alpha$-actinin were frequently associated with antibodies to single stranded DNA [77, 78].

10-20\% of patients with HCV-related CLD also had SMA [41-44]. However, SMA in most sera of patients with HCV-related CLD lacked in the reactivities with F-actin [43, 59]. Non-muscle myosin seems to be a candidate for a target antigen of SMA in those patients [79].

\section{Clinical significance in predicting disease activity}

AIH patients with anti-F-actin had the clinical characteristics of younger onset than those without anti-F-actin [80]. However, the emergence of anti-F-actin did not necessarily reflect more advanced staging. In contrast, double reactivity with $\mathrm{F}$-actin and $\alpha$-actinin defined a severe form of type 1 AIH [77].

Approximately, $30 \%$ of patients with AIH/PBC overlap syndrome had SMA [51, 81]. Seropositivity for SMA is one of the components for the Paris criteria, which is an international diagnostic criterion for AIH/PBC overlap syndrome proposed by Chazouillerres et al. [82].

Patients with HCV-related CLD seropositive for SMA had more severe interface hepatitis than those seronegative for SMA [83]. However, the emergence of non-organspecific autoantibodies (NOSA), including ANA, SMA and anti-LKM1, did not necessarily affect the anti-viral treatment in patients with $\mathrm{CH}-\mathrm{C}$ [43, 84].

\section{Prognostic value}

Czaja and his colleagues [80] elucidated that type $1 \mathrm{AIH}$ patients seropositive for anti-F-actin developed liver failure and required liver transplantation more frequently than 
those seronegative for anti-F-actin. In fact, we recently revealed that anti-F-actin were associated with relapse in AIH patients after withdrawal of treatment with corticosteroid [85]. On the other hand, anti- $\alpha$-actinin can be recognized as an independent predictor of a poor responder to corticosteroid [86].

\section{Antibodies to liver kidney microsomes (anti-LKM)}

\section{Diagnostic value}

Autoantibodies to liver kidney microsomal proteins (antiLKM) are closely associated with several kinds of liver diseases including type $2 \mathrm{AIH}$, drug-induced hepatitis, autoimmune polyendocrinopathy-candidiasis-ectodermal dystrophy (APECED), HCV and HDV infections [87]. Anti-LKM are directed against the proximal renal tubules and cytoplasms of hepatocytes [88].

The antibody to LKM type 1(anti-LKM1) is a major serological hallmark of type $2 \mathrm{AIH} \mathrm{[89],} \mathrm{but} \mathrm{is} \mathrm{also} \mathrm{found} \mathrm{in}$ some sera of patients with chronic hepatitis $\mathrm{C}$ ( $\mathrm{CH}-\mathrm{C})$ [90]. The major target antigen of anti-LKM1 was identified as cytochrome monooxygenase p450 IID6 (CYP2D6) [91]. The most immunodominant epitope of CYP2D6 was the C-terminal portion of the molecule [92]. The amino acid (aa) sequence between 316 and 327, which was exposed on the surface of the molecule, appeared to be the region capable of distinguishing type $2 \mathrm{AIH}$ from HCV infection [93].

Recently, molecular mimicry between the aa sequence 252-271 of CYP2D6 and HCV E1 was shown [94]. The cross-reactivity took place in patients with chronic hepatitis C, who possessed the HLA B51 allotype [94]. Moreover, CYP2A6, CYP2E1 and CYP3A4 were identified as novel target autoantigens of anti-LKM1 in patients with chronic hepatitis C seropositive for anti-LKM1, respectively [95]. Therefore, a heterogeneous autoimmune reaction may take place in patients with chronic hepatitis $\mathrm{C}$ seropositive for anti-LKM1.

Antibodies to LKM type 2 (anti-LKM2) have been detected in the sera of patients with tienilic acid-induced hepatitis [96]. CYP2C9 has been identified as the target antigen of anti-LKM2. The binding of an active metabolite to CYP2C9 becomes antigenic and eventually leads to the production of these autoantibodies. Antibodies to LKM type 3 (Anti-LKM3) are primarily present in the sera of patients with HDV infection, and are directed against uridine diphosphate glucuronosyltransferase (UGT) [96].

\section{Clinical significance in predicting disease activity and concurrent disease}

The clinical characteristics of type $2 \mathrm{AIH}$ are quite different from those of type $1 \mathrm{AIH}$. AIH patients with anti-
LKM1 are younger at disease onset, and show more severe necroinflammation of the liver including higher levels of serum bilirubin and transaminases [89].

A recent article elucidated that the emergence of antiLKM1 reduced the CYP2D6 metabolic activity in patients with CH-C seropositive for anti-LKM1 [97]. On the other hand, it is remarkable that CH-C patients with anti-LKM1 were frequently associated with autoimmune thyroiditis [98, 99].

\section{Antibodies to soluble liver antigen (anti-SLA)}

\section{Diagnostic value}

Antibodies to soluble liver antigen (anti-SLA) were originally identified as a serological marker for type $3 \mathrm{AIH}$ [100]. The molecular target of anti-SLA has been established as a 422 amino acid protein, which is a transfer ribonucleoprotein involved in selenocysteine insertion $\left(\mathrm{tRNP}^{(\mathrm{ser}) \mathrm{sec}}\right)$ and recently renamed SEPSECS [Sep (Ophosphor-serine) tRNA:Sec (selenocysteine) tRNA synthase] by the Nomencluster Commission of the Human Genome Organization [20]. Anti-SLA turned out to be identical to the antibody to liver pancreas (anti-LP) [101]. The isotypes of anti-LP were previously investigated among patients with AIH. A predominant type of anti-LP in patients with AIH was the IgG1 type. None of the patients with AIH had $\mathrm{IgG} 3$ and IgG4 types of anti-LP [102].

Clinical, serological, and genetic studies have elucidated that patients with AIH seropositive for anti-SLA did not define a distinct subgroup of $\mathrm{AIH}$, but, rather belonged to type 1 AIH [103, 104]. It is of importance that the presence of anti-SLA is highly specific to type $1 \mathrm{AIH}$, although antiSLA are detected in the sera of only $15 \%$ of North American patients with type 1 AIH [16]. Furthermore, a strong association of DRB $1 * 0301$ with anti-SLA has been reported as the genetic background in patients with $\mathrm{AIH}$ [105].

Anti-SLA was rarely detected in patients with $\mathrm{CH}-\mathrm{C}$, type 2 AIH and PSC [106, 107]. Vitozzi and colleagues [108] revealed that the prevalence of anti-SLA was increased when anti-LKM1 was present in patients with HCV-related CLD.

\section{Clinical significance in predicting disease activity}

Several articles confirmed that AIH patients with anti-SLA displayed a more severe clinical course, and they required longer duration of treatment or had higher frequency of liver transplantation than AIH patients without anti-SLA [106, 109]. 


\section{Prognostic value}

Anti-SLA can be the most promising serological markers to identify patients with AIH who will experience a relapse after withdrawal of the treatment with corticosteroid [16, 110]. Therefore, patients with AIH seropositive for antiSLA at presentation may have difficulties in the immunosuppressive treatment.

\section{Antimitochondrial antibodies (AMA)}

\section{Diagnostic value}

AMA is considered to be the diagnostic hallmark of PBC, because the autoantibodies are detected in up to 90-95\% of patients with PBC [111]. AMA recognizes the highly conserved regions of 2-oxoacid dehydrogenase complexes (2-OADC), which exist in the inner membrane of mitochondria. The major autoantigen of 2-OADC turns out to be the E2 subunit of the pyruvate dehydrogenase complex (PDC-E2) [112]. AMA selectively reacts with the E2 subunit of the branched chain 2-oxoacid dehydrogenase complex (BCOADC-E2), the E2 component of the 2-oxoglutarate dehydrogenase complex (OGDC-E2), the dihydrolipoamide dehydrogenase (E3)-binding protein (E3BP), and the E1 $\alpha$ subunit of the pyruvate dehydrogenase complex (PDC-E1 $\alpha$ ) [113]. Therefore, analysis of the IgA and IgG types of AMA by the ELISA technique using recombinant MIT3 antigen, which contains the three immunodominant epitopes PDC-E2, BCOADC-E2 and OGDC-E2 increases the specificity of PBC [114].

Mucosal immunity contributes to the pathogenesis of PBC. Tanaka and colleagues [115] revealed that the $\operatorname{IgA}$ type of AMA was detected in 57 (69\%) of 83 patients with $\mathrm{PBC}$, and that most of these AMA belonged to secretorytype IgA. Positive correlation of IgA class anti-OGDC with histopathological stage was also shown [116]. Another report documented that transcytosis of $\operatorname{IgA}$ was mediated by the polymeric immunoglobulin receptor (pIgR), and that co-localization of PDH-E2 and IgA was observed in epithelial cells transfected with pIgR [117]. These data support the hypothesis that IgA-PDC-E2 immune complexes are transported to the biliary epithelial cells by the way of pIgR. Furthermore, Matsumura and colleagues [118] provided evidence that transcytosis of AMA-IgA caused caspase activation, resulting in apoptosis of bile duct epithelia.

AMA is also present in the sera of patients with AIH. Nezu and colleagues [119] documented that AMA was found in 14 of 41 (34\%) patients with type 1 AIH by immunoblotting using beef heart mitochondria proteins as the antigens. However, serological parameters including ANA profile and biochemistry, and histological findings such as bile duct lesions were almost similar regardless of AMA status.

According to the report by Ramos-Casals' group, AMA was detected in $18(8 \%)$ of 237 patients with HCV-related CLD [120]. However, only 5 (28\%) of 18 patients exhibited histological findings compatible with PBC. Twelve $(67 \%)$ of these 18 patients had concomitant autoimmune diseases including Sjögren's syndrome, systemic sclerosis and systemic lupus erythematosus (SLE). Four $(22 \%)$ of 18 patients proceeded with neoplasia including HCC.

\section{Clinical significance in predicting disease activity}

Titers of AMA do not appear to be correlated with disease severity in patients with PBC [121]. There was an interesting article on the comparison of histological activities between AMA-positive and AMA-negative patients with PBC. AMA-negative patients with PBC exhibited more severe bile duct damages. This damage was associated with the infiltration of CD20-positive B cells into the liver [122]. On the other hand, ductular invasion of CD5-positive cells was more frequently observed in the portal area of the liver from AMA-negative patients with PBC [122].

Aric and his colleagues [123] investigated the clinical significance of AMA in patients with AIH/PBC overlap syndrome. Nine of 21 patients with AIH/PBC overlap syndrome had AMA. ANA and/or SMA were present in the sera of those patients without AMA. Those patients without AMA had more severe bile ductular damage and hepatic fibrosis.

IgG subclasses of AMA were also analyzed in the sera from patients with PBC. The IgG3 subtype of AMA defined more advanced disease activity and more frequent liver cirrhosis [124]. Kawai and his colleagues documented the correlation between the IgG2 subclass of AMA and the innate immune response against bacterial particles [125].

Strikingly, Leung et al. [126] revealed the presence of autoantibodies against PDC-E2, BCOAD-E2, and OGDCE2 during acute liver failure. However, these autoantibodies immediately disappeared after the recovery of hepatic reserve. These findings support the hypothesis that liver damage caused by oxidative stress may trigger the production of AMA.

\section{Antineutrophil cytoplasmic antibodies (ANCA)}

\section{Diagnostic value}

ANCA are directed against the cytoplasmic constituents of neutrophilic granulocytes. These autoantibodies are largely divided into two groups by the staining pattern on ethanolfixed granulocytes as substrates by the IIF method: 
perinuclear pattern (pANCA) and cytoplasmic pattern (cANCA) [127]. Classical pANCA were often detected in the sera of patients with microscopic polyangiitis, and myeloperoxidase has been identified as their target antigen. On the other hand, cANCA are commonly found in the sera of patients with Wegener's granulomatosis, and primarily recognize proteinase 3 .

pANCA are present in patients with PSC and type $1 \mathrm{AIH}$ [128]. Actin [129] or high mobility group (HMG) nonhistone proteins [130] were regarded as candidates for the target antigens of pANCA in patients with type 1 AIH. pANCA in patients with PSC exhibits an atypical staining pattern that has heterogeneous rim-like staining of the nuclear periphery and multiple intra-nuclear spots [131]. Terjung and colleagues [132] identified a 50-kD nuclear envelope protein of myeloid cells as a novel target antigen of pANCA which showed atypical perinuclear staining.

A recent study documented that the IgG subclasses of pANCA in patients with PSC were IgG1 and IgG3 isotypes, while that in patients with type $1 \mathrm{AIH}$ was IgG1dominant [133]. pANCA in patients with PSC was neutrophil-specific, whereas that in patients with type $1 \mathrm{AIH}$ reacted with neutrophils and monocytes [133] The IgA type of pANCA was observed in autoimmune liver disease [134]. The IgA type of pANCA had no disease-specificity, although the prevalence of IgA class pANCA was higher in patients with type $1 \mathrm{AIH}$ than in patients with PSC. Recently, Terjung et al. [135] elucidated that p-ANCA in autoimmune liver disease were directed against human beta tubulin isotype 5 as well as bacterial precursor protein FtsZ, which has proposed a novel concept on the potential role of microorganisms in the autoimmune liver disease.

\section{Clinical significance in predicting disease activity}

It is of interest that Roozendaal and his colleagues [136] elucidated that ANCA were associated with decreased serum albumin and increased alkaline phosphatase levels in patients with PSC, suggesting that the presence of ANCA in patients with PSC may predict severe disease activity.

\section{Autoantibodies to asialoglycoprotein receptors (anti-ASGPR)}

\section{Diagnostic value}

Asialoglycoprotein receptor (ASGPR) is a transmembrane glycoprotein, which was previously identified as a liverspecific autoantigen [137]. Antibodies to ASGPR (antiASGPR) are frequently found in the sera of patients with type $1 \mathrm{AIH}$, although some patients with $\mathrm{PBC}$, viral hepatitis and alcoholic liver disease have these autoantibodies, indicating that these antibodies lack in the specificity for type 1 AIH $[138,139]$. However, anti-ASGPR have diagnostic value in patients with $\mathrm{AIH}$, who are seronegative for conventionally tested autoantibodies including ANA, SMA, anti-LKM1, and anti-SLA [140]. These antibodies are mainly detected by an EIA, a RIA or an immunoblot method. However, a standardized assay for detection of anti-ASGPR has not yet been determined [141]. Recently, a commercially available ELISA kit using purified rabbit ASGPR as a target antigen was developed, and the efficacy of the kit was shown by Hausdorf et al. [142].

\section{Clinical significance in predicting disease activity}

AIH patients with anti-ASGPR had higher IgG levels and more severe histological activity than those without antiASGPR [141, 143]. A recent study also revealed that the titers of anti-ASGPR were associated with serum ALT levels, suggesting that these antibodies can be monitored for a disease activity [142].

\section{Prognostic value}

The presence of anti-ASGPR at presentation might predict relapse after drug withdrawal in patients with AIH [139, 144]. The persistence or disappearance of these antibodies often reflected the adequacy of the treatment response in those patients.

\section{Autoantibodies to tumor-associated antigens (anti-TAA)}

\section{Diagnostic value}

Numerous tumor-associated antigens (TAAs), including p53, c-myc, cyclin B1, IGF-II mRNA binding proteins (IMPs) and survivin, have been identified from the patients with HCC (Table 3) [145]. Most of these TAAs are primarily engaged in essential cellular function including DNA replication, DNA transcription, and pre-mRNA splicing and translation [146].

We previously examined the prevalence of antibodies to p53, c-myc, survivin and IMPs in the sera of patients with HCC. Eight of $86(9.3 \%)$ sera of HCC patients had one or more of these autoantibodies [147]. It is of interest that the serum level of alpha-fetoprotein (AFP), the tumor marker for HCC, remained within normal limits in 7 of 8 HCC patients with anti-TAA, suggesting that the antibodies to TAA are complimentary serological markers for HCC. It is notable that HCC patients with circulating anti-IMPs had overexpression of IMPs in the tumor cells, indicating that these autoantibodies to TAAs were produced by an antigen-driven immune system [148]. Moreover, the titers of anti-TAA were often increased by the development of 
Table 3 Tumor-associated antigens identified from patients with $\mathrm{HCC}$ and their functions

\begin{tabular}{lll}
\hline $\begin{array}{l}\text { Intracellular } \\
\text { component }\end{array}$ & Autoantigens & Biological functions \\
\hline Nucleus & $\begin{array}{c}\text { DNA } \\
\text { topoisomerase } \\
\text { II }\end{array}$ & DNA replication/transcription \\
& CENP-F & Mitotic function \\
& HCC-1 & mRNA splicing \\
& Cyclin B1 & Cell-cycle progression \\
& Fibrillarin & rRNA processing \\
& NOR-90/hUBF & RNA pol I transcription \\
& B23 & Ribosome maturation \\
& Ku86 & DNA doule-strand break repair \\
p62/IMP2 & Regulation of IGF-II mRNA \\
Cytoplasm & Koc/IMP3 & Regulation of IGF-II mRNA \\
& Golgi & Processing, transporting and \\
& & sorting of intracellular proteins \\
\hline
\end{tabular}

HCC [149]. We also revealed that antibodies to p53 and IMP3 in a patient with HCC were detected prior to the clinical diagnosis of HCC [147].

A recent article by Nomura and colleagues [150] demonstrated that circulating antibodies to $\mathrm{Ku} 86$, a DNAbinding nuclear autoantigen, were potential biomarkers for HCV-related HCC. The titers of anti-Ku86 had a tendency to be associated with the severity of $\mathrm{Ku} 86$ expression in the tumor cells. Furthermore, the titers of anti-Ku86 seemed to be independent of the serum AFP levels in patients with HCC.

Antibodies to p53 (anti-p53) are also found in patients who are suffering from autoimmune disease including SLE, type 1 diabetes mellitus, and chronic thyroiditis [151, 152]. The efficacy of anti-p53 was shown in discriminating AIH patients from PBC patients [153, 154]. Interestingly, anti-p53 was associated with anti-dsDNA, suggesting that DNA damage may trigger the production of anti-p53 [154].

\section{Antibodies to stress proteins}

\section{Clinical significance in predicting disease activity}

Degenerated proteins initiated by oxidative stress can be immunogenic. Recently, oxidatively modified autoantigens, including oxidized low-density lipoprotein (ox-LDL) and 8-oxodeoxyguanine, were identified from patients with SLE [155].

Hepatic steatosis is one of the common metabolic abnormalities caused by HCV-induced oxidative stress [156]. We recently elucidated that titers of antibodies to ox-LDL were significantly associated with the severity of hepatic steatosis in patients with CH-C [157], indicating that the autoimmune response was involved in the process of hepatic steatosis (Table 4). However, we failed to show the correlations between titers of anti-ox-LDL and the severity of insulin resistance in patients with HCV-related CLD. Vidali and his colleagues also demonstrated that titers of antibodies to malondialdehyde (MDA) in severe steatosis were significantly higher than those with mild or no steatosis among patients with CH-C [158].

CYP 2E1 is an endoplasmic monooxygenase and major source of oxidative stress in microsomes [159]. Overexpression of CYP 2E1 is well recognized in the liver of patients with NASH [160] and CH-C [161] as well as alcoholic liver disease [162]. The hepatic expression of CYP 2E1 is related to the severity of hepatic steatosis in those patients [161]. Recently, approximately $40 \%$ of patients with CH-C had antibodies to CYP2E1 [163]. The molecular mimicry between HCV NS5B and CYP2E1 may trigger the production of these autoantibodies in patients with CH-C [164]. It is of interest that the emergence of anti-CYP 2E1 was independent of hepatic steatosis in $\mathrm{CH}-$ $\mathrm{C}$ patients [163]. However, $\mathrm{CH}-\mathrm{C}$ patients with antibodies to CYP 2E1 had more severe necroinflammation in the liver than those without anti-CYP2E1 [163]. Another study revealed the efficacy of antibodies to CYP 2E1 in patients with drug-induced patients. Njoku and his colleagues [165]

Table 4 Autoantibodies to stress proteins in liver disease

\begin{tabular}{llll}
\hline Autoantibodies & Molecular target & Associated liver disease & Clinical significance \\
\hline Anti-ox-LDL & ox-LDL & HCV & Correlation with hepatic steatosis \\
Anti-MDA & MDA & HCV, NASH & Correlation with hepatic steatosis \\
Anti-CYP2E1 & CYP2E1 & Type 1 AIH, HCV, alcohol, halothane-induced hepatitis & \\
Anti-cardiolipin & Cardiolipin & Type 1 AIH, PBC, NASH, alcohol, HCV & IgG4 type of anti-CYP2E1 correlation with \\
& & HCV & hepatic fibrosis \\
Anti-SOD & SOD & AIH, HCV & Correlation with anti-HSP65 \\
Anti-HSP & HSP65 & AIH & Inverse correlation with disease-activity \\
& HSP70 & HCV &
\end{tabular}


elucidated that the IgG4 type of antibodies to CYP 2E1 were specific to the patients with anesthetic-induced hepatitis.

Antibodies to cardiolipin (anti-cardiolipin), the serological hallmark of antiphospholipid antibodies syndrome, are detected in the sera of patients with type 1 AIH, PBC, PSC, HBV- and HCV-related CLD, and alcoholic liver disease [166-169]. However, most of those patients with anti-cardiolipin lacked in the category for the antiphospholipid antibody syndrome [168].

The association between anti-cardiolipin and oxidative stress was previously shown in patients with CH-C [169]. Patients with HCV infection seropositive for anti-cardiolipin developed more advanced hepatic fibrosis than those seronegative for anti-cardiolipin [169], as patients with AIH seropositive for anti-cardiolipin did [168]. The emergence of anti-cardiolipin might imply concurrent oral lichen planus in patients with $\mathrm{CH}-\mathrm{C}$ [170], although it remains controversial.

Miyata and his colleagues [171] exhibited that patients with AIH had significantly higher titers of antibodies to superoxide dismutase (SOD) than patients with $\mathrm{CH}-\mathrm{C}$, or SLE. They suggested that the autoimmune response derived from molecular mimicry between human SOD and mycobacterial heat shock protein (HSP) 65, because titers of anti-SOD were correlated with titers of anti-HSP65. Another study reported that antibodies to HSP70 were also detected in 14 (24\%) of 59 patients with CH-C [172]. The article showed that titers of anti-HSP70 were inversely correlated with serum ALT levels and loads of HCV-RNA.

\section{Interferon-induced autoantibodies}

\section{Diagnostic value}

It has been well recognized that treatment with interferon- $\alpha$ (IFN- $\alpha$ ) or pegylated IFN- $\alpha$ initiates various kinds of autoimmune diseases [173]. Therefore, $\mathrm{CH}-\mathrm{C}$ patients treated with IFN- $\alpha$ occasionally develop autoimmune diseases including autoimmune thyroid disease (Graves' disease and Hashimoto's thyroiditis), type 1 diabetes mellitus (DM) and type 1 AIH [174]. Approximately $10 \%$ of CH-C patients had thyroid autoantibodies including thyroid microsome antibodies, thyroglobulin antibodies and antibodies to thyroid peroxidase during treatment with IFN- $\alpha$ / pegylated IFN- $\alpha[175,176]$. Antibodies to glutamic acid decarboxylase (GAD) were also detected in 1-3\% of $\mathrm{CH}-$ $\mathrm{C}$ patients during treatment with IFN- $\alpha /$ Pegylated IFN- $\alpha$, respectively [176]. The emergence of these autoantibodies was restricted to the specific HLA haplotypes. Patients who developed Type 1 DM were genetically restricted to HLA DRB1-DQB1 haplotype [177], while IFN-induced autoimmune thyroiditis had genetic susceptibility to HLA A2 in the Japanese population [178], or HLA DRB $1 * 11$ in the Caucasian population [179].

Parana and his colleagues [180] documented that antibodies to the Golgi complex appeared in three patients with $\mathrm{CH}-\mathrm{C}$ during treatment with pegylated IFN. The authors paid attention to the progressive disease in those patients with anti-Golgi complex.

Recently, a novel autoantibody induced by pegylated IFN and ribavirin was found in sera of patients with $\mathrm{CH}-\mathrm{C}$. This antibody was named antibodies to cytoplasmic rods and rings, which consisted of rod-like cytoplasmic structures and rings [181, 182]. However, the clinical relevance of this autoantibody remains uncertain. Vaquez-Del Mercado and his colleagues [183] speculated that antibodies to argonaute 2 (Su antigen), a miRNA-binding protein, were also induced by IFN.

\section{Clinical significance in predicting the outcome of anti-viral treatment}

NOSA including ANA, SMA and anti-LKM1 at base line did not generally affect the outcome of anti-viral treatment in patients with $\mathrm{CH}-\mathrm{C}[43,84]$. However, ANA at the end of treatment, or an increase in titers of SMA during the treatment can predict the unfavorable outcome in $\mathrm{CH}-\mathrm{C}$ patients [184].

The emergence of antibodies to thyroid peroxidase at base line can predict the progression to IFN-induced thyroid disease in patients with $\mathrm{CH}-\mathrm{C}$ [185].

Conflict of interest Takashi Himoto and Mikio Nishioka have no conflict of interest to declare.

\section{References}

1. Tan EM (1989) Antinuclear antibodies: diagnostic markers for autoimmune disease and probes for cell biology. Adv Immunol 44:93-151

2. Tan EM (1991) Autoantibodies in pathology and cell biology. Cell 67:841-842

3. Czaja AJ, Homburger HA (2001) Autoantibodies in liver disease. Gastroenterology 120:239-249

4. Invernizzi P, Lleo A, Podda M (2007) Interpreting serological tests in diagnosing autoimmune liver diseases. Semin Liver Dis 27:161-172

5. Zeman MV, Hirschfield GH (2010) Autoantibodies and liver disease: uses and abuses. Can J Gastroenterol 24:225-231

6. Zachou K, Rigopoulou E, Dalekos GN (2004) Autoantibodies and autoantigens in autoimmune hepatitis: important tools in clinical practice and to study pathogenesis of the disease. J Autoimmune Dis 1:1-17

7. Tahiri F, Nenour F, Huguet $S$ et al (2008) Identification of plasma membrane autoantigens in autoimmune hepatitis type 1 using a proteomics tool. Hepatology 47:93-7948

8. Song Q, Liu G, Hu S et al (2010) Novel autoimmune hepatitisspecific autoantigens identified using protein microarray technology. J Proteome Res 9:30-39 
9. Takashima M, Kuramitsu Y, Yokoyama Y et al (2006) Proteomic analysis of autoantibodies in patients with hepatocellular carcinoma. Proteomics 6:3894-3900

10. Tamer G, Mert M, Tamer I et al (2011) Effects of thyroid autoimmunity on abdominal obesity and hyperlipidemia. Endokrynol Pol 6:421-428

11. Winer DA, Winer S, Shen L et al (2011) B cells promotes insulin resistance through modulation of $\mathrm{T}$ cells and production of pathogenic IgG antibodies. Nat Med 17:610-617

12. Umemura T, Zen Y, Hamano H et al (2007) IgG4 associated autoimmune hepatitis: a differential diagnosis for classical autoimmune hepatitis. Gut 56:1471-1472

13. Harada K, Shimoda S, Sato Y et al (2009) Periductal interleukin-17 production in association with biliary innate immunity contributes to the pathogenesis of cholangiopathy in primary biliary cirrhosis. Clin Exp Immunol 157:261-270

14. Czaja AJ (2012) Autoantibody-negative autoimmune hepatitis. Dig Dis Sci 57:610-624

15. Bogdanos DP, Invernizzi P, Mackay IR, Vergani D (2008) Autoimmune liver serology: current diagnostic and clinical challenges. World J Gastroenterol 14:3374-3387

16. Czaja AJ (2010) Autoantibodies as prognostic markers in autoimmune liver disease. Dig Dis Sci 55:2144-2161

17. Longhi MS, Ma Y, Bogdanos DP et al (2004) Impairment of $\mathrm{CD} 4+\mathrm{CD} 25+$ regulatory $\mathrm{T}$ cells in autoimmune liver disease. J Hepatol 41:31-37

18. Lan RY, Cheng C, Lian ZX et al (2006) Liver-targeted and peripheral blood alterations of regulatory $\mathrm{T}$ cells in primary biliary cirrhosis. Hepatology 43:729-737

19. Santodomingo-Garzon T, Swain MG (2011) Role of NKT cells in autoimmune liver disease. Autoimmun Rev 10:793-800

20. Czaja AJ, Manns MP (2010) Advances in the diagnosis, pathogenesis and management of autoimmune hepatitis. Gastroenterology 139:58-72

21. Migita K, Ilyassova B, Kovzel EF et al (2010) Serum BAFF and APRIL levels in patients with PBC. Clin Immunol 134:217-225

22. Toubi E, Gordon S, Kessel A et al (2006) Elevated serum B-lymphocyte activating factor (BAFF) in chronic hepatitis C virus infection: association with autoimmunity. J Autoimmun 27:134-139

23. Bogdanos DP, Choudhuri K, Vergani D (2001) Molecular mimicry and autoimmune liver disease: virtuous intentions, malign consequences. Liver 21:225-232

24. Bogdanos DP, Baum H, Grasso A, et al (2004) Microbial mimics are major targets of crossreactivity with human pyruvate dehydrogenase in primary biliary cirrhosis. J Hepatol 40:31-39

25. Rieger R, Leung PSC, Jeddeloh MR et al (2006) Identification of 2-nonynoic acid, a cosmetic component, as a potential trigger of primary biliary cirrhosis. J Autoimmun 27:7-16

26. Moritoki Y, Lian ZX, Wulff $\mathrm{H}$ et al (2007) AMA production in primary biliary cirrhosis is promoted by the TLR9 ligand CpG and suppressed by potassium channel blockers. Hepatology 45:314-322

27. Czaja AJ, Carpenter HA, Santrach PJ, Moore SB (1993) Genetic predispositions for the immunological features of chronic active hepatitis. Hepatology 18:816-822

28. Czaja AJ, Morshed SA, Parveen S et al (1997) Antibodies to single-stranded and double-stranded DNA in antinuclear antibody-positive type 1 autoimmune hepatitis. Hepatology 26: 567-572

29. Alvarez F, Berg PA, Bianchi FB et al (1999) International autoimmune hepatitis group report: review of criteria for diagnosis of autoimmune hepatitis. J Hepatol 31:929-938

30. Nishioka M, SMorshed SA (1999) Heterogeneity of anti-nuclear antibodies in autoimmune liver disease. Biomed Pharmacother 53:293-300
31. Czaja AJ, Nishioka M, Morshed SA, Hachiya T (1994) Patterns of nuclear immunofluorescence and reactivities to recombinant nuclear antigens in autoimmune hepatitis. Gastroenterology 107:200-207

32. Huget S, Labas V, Duclos-Vallee JC et al (2004) Heterogeneous nuclear ribonucleoprotein $\mathrm{A} 2 / \mathrm{B} 1$ identified as an autoantigen in autoimmune hepatitis by proteome analysis. Proteomics 4: 1341-1345

33. Invernizzi P, Selmi C, Ranftier C, Podda M, Wesierska-Gadek J (2005) Antinuclear antibodies in primary biliary cirrhosis. Semin Liver Dis 25:298-310

34. Nickowitz RE, Worman HJ (1993) Autoantibodies from patients with primary biliary cirrhosis recognize a restricted region within the cytoplasmic tail of nuclear pore membrane glycoprotein Gp210. J Exp Med 178:2237-2242

35. Wesierska-Gadek J, Hohenuer H, Hitchman E, Penner E (1996) Autoantibodies against nucleoporin p62 constitute a novel marker of primary biliary cirrhosis. Gastroenterology 110: 840-847

36. Szostecki C, Krippner H, Penner E, Bautz FA (1987) Autoimmune sera recognize a $100 \mathrm{kD}$ nuclear protein antigen $(\mathrm{sp}-100)$. Clin Exp Immunol 68:108-116

37. Strendorf T, Guldner HH, Szostecki C et al (1995) Two nuclear dot-associated protein, PML and Sp100, are often co-autoimmnogenic in patients with primary biliary cirrhosis. Scand J Immunol 42:257-268

38. Janka C, Selmi C, Gershwin ME et al (2005) Small ubiquitinrelated modifiers: a novel and independent class of autoantigens in primary biliary cirrhosis. Hepatology 41:609-616

39. Granito A, Yang WH, Muratori L et al (2010) PML nuclear body component $\mathrm{Sp} 140$ is a novel autoantigen in primary biliary cirrhosis. Am J Gastroenterol 105:125-131

40. Duarte-Rey C, Bogdanos D, Yang CY et al (2012) Primary biliary cirrhosis and the nuclear pore complex. Autoimmun Rev (Epub)

41. Clifford BD, Donahue D, Smith L et al (1995) High prevalence of serological markers of autoimmunity in patients with chronic hepatitis C. Hepatology 21:613-619

42. Lenzi M, Bellentani S, Saccoccio G et al (1999) Prevalence of non-organ-specific autoantibodies and chronic liver disease in the general population: a nested case-control study of the Dionysos cohort. Gut 45:435-441

43. Cassani F, Cataleta M, Valentini P et al (1997) Serum autoantibodies in chronic hepatitis C: comparison with autoimmune hepatitis and impact on the disease profile. Hepatology 26: $561-566$

44. Himoto T, Nishioka M (2008) Autoantibodies in hepatitis C virus-related chronic liver disease. Hepat Mon 8:295-303

45. Gregorio GV, Choudhuri K, Ma Y et al (2003) Mimicry between the hepatitis $\mathrm{C}$ virus polyprotein and antigenic targets of nuclear and smooth muscle antibodies in chronic hepatitis $\mathrm{C}$ virus infection. Clin Exp Immunol 133:404-413

46. Li L, Cheng M, Huang DY, Nishioka M (2000) Freauency and significance of antibodies to chromatin in autoimmune hepatitis type 1. J Gastroenterol Hepatol 15:1176-1182

47. Czaja AJ, Shums Z, Binder WL et al (2003) Frequency and significance of antibodies to chromatin in autoimmune hepatitis. Dig Dis Sci 48:1658-1664

48. Czaja AJ, Ming C, Shirai M, Nishioka M (1995) Frequency and significance of antibodies to histones in autoimmune hepatitis. J Hepatol 23:32-38

49. Chen M, Shirai M, Czaja AJ et al (1998) Characterization of anti-histone antibodies in patients with type 1 autoimmune hepatitis. J Gastroenterol Hepatol 13:483-490

50. Tsuchiya K, Kiyosawa K, Imai H et al (1994) Detection of antidouble and anti-single stranded DNA antibodies in chronic liver 
disease: significance of anti-double stranded DNA antibody in autoimmune hepatitis. J Gastroenterol 29:152-158

51. Muratori P, Granito A, Pappas G et al (2009) The serological profiles of autoimmune hepatitis/primary biliary cirrhosis overlap syndrome. Am J Gastroenterol 104:1420-1425

52. Himoto T, Murota M, Yoneyama H et al (2010) Clinical characteristics of patients with autoimmune hepatitis seropositive for anticentromere antibody. Hepatol Res 40:786-792

53. Muratori P, Muratori L, Ferrari R et al (2003) Characterization and clinical impact of antinuclear antibodies in primary biliary cirrhosis. Am J Gastroenterol 98:431-437

54. Bogdanos DP, Baum H, Butler P et al (2003) Association between the primary biliary cirrhosis specific anti-sp100 antibodies and recurrent urinary tract infection. Dig Liver Dis 35:801-805

55. Rigopoulou EI, Davies ET, Pares A et al (2005) Prevalence and clinical significance of isotype specific antinuclear antibodies in primary biliary cirrhosis. Gut $54: 528-532$

56. Dorner T, Held C, Trebeljahr G et al (1994) Serological characteristics in primary biliary cirrhosis associated with Sicca syndrome. Scand J Gastroenterol 29:655-660

57. Granito A, Muratori P, Muratori L et al (2007) Antibodies to SS$\mathrm{A} / \mathrm{Ro}-52 \mathrm{kD}$ and centromere in autoimmune liver disease: a clue to diagnosis and prognosis of primary biliary cirrhosis. Aliment Pharmacol Ther 26:831-838

58. Shoji I, Takagi T, Kasukawa R (1992) Anti-centromere antibody and CREST syndrome in patients with primary biliary cirrhosis. Intern Med 31:1348-1355

59. Chretien P, Chousterman M, Alsamad IA et al (2009) Nonorgan-specific autoantibodies in chronic hepatitis $\mathrm{C}$ patients: associations with histological activity and fibrosis. J Autoimmun 32:201-205

60. Peng YC, Hsieh SC, Yang DY et al (2001) Expression and clinical significance of antinuclear antibody in hepatitis $\mathrm{C}$ virus infection. J Clin Gastroenterol 33:402-406

61. Luo JC, Hwang SJ, Li CP et al (1998) Clinical significance of serum auto-antibodies in Chinese patients with chronic hepatitis $\mathrm{C}$ : negative role of serum viral titre and genotype. J Gastroenterol Hepatol 13:475-479

62. Loria P, Lonardo A, Leonardi F et al (2003) Non-organ-specific autoantibodies in nonalcoholic fatty liver disease: prevalence and correlates. Dig Dis Sci 48:2173-2181

63. Adams LA, Lindor KD, Angulo PA (2004) The prevalence of autoantibodies and autoimmune hepatitis in patients with nonalcoholic fatty liver disease. Am J Gastroenterol 99: $1316-1320$

64. Yatsuji S, Hashimoto E, Kaneda $\mathrm{H}$ et al (2005) Diagnosing autoimmune hepatitis in nonalcoholic fatty liver disease: is the International Autoimmune Hepatitis Group scoring system useful? J Gastroenterol 40:1130-1138

65. Nakamura M, Kondo H, Mori T et al (2007) Anti-gp210 and anti-centromere antibodies are different risk factors for the progression of primary biliary cirrhosis. Hepatology 45: $115-127$

66. Montano-Loza AJ, Shums Z, Norman GL, Czaja AJ (2012) Prognostic implications of antibodies to Ro/SSA and soluble liver antigen in type 1 autoimmune hepatitis. Liver Int 32:85-92

67. Tojo J, Ohira H, Suzuki T et al (2002) Clinicolaboratory characteristics of patients with primary biliary cirrhosis associated with CREST symptoms. Hepatol Res 22:187-195

68. Himoto T, Nakai S, Kinekawa F et al (2009) Clinical characteristics of patients with hepatitis $\mathrm{C}$ virus-related chronic liver disease seropositive for anticentromere antibody. Dig Dis Sci 54:360-368

69. Kurki P, Virtanen I (1984) The detection of human antibodies against cytoskeletal components. J Immunol Methods 67:209-223
70. Lidman K, Biberfeld G, Fagraeus A et al (1976) Anti-actin specificity of human smooth muscle antibodies in chronic active hepatitis. Clin Exp Immunol 24:266-272

71. Soares A, Cunha R, Rodrigues F, Riberio H (2009) Smooth muscle antibodies with F-actin specificity. Autoimmun Rev 8:713-716

72. Nishioka M, Watanabe S, Kobayashi K, Nakamura T (1983) Rabbit autoantibodies to actin induced by immunization with heterologous actins; a possible mechanism of smooth muscle antibody production. Clin Exp Immunol 53:159-164

73. Fusconi M, Cassani F, Zauli D et al (1990) Anti-actin antibodies: a new test for an old problem. J Immunol Methods 130:1-8

74. Villalta D, Bizzaro N, Da Re M et al (2008) Diagnostic accuracy of four different immunological methods for the detection of anti-F-actin autoantibodies in type 1 autoimmune hepatitis and other liver-related disorders. Autoimmunity 41:105-110

75. Frenzel C, Herkel J, Luth S et al (2006) Evaluation of F-actin ELISA for the diagnosis of autoimmune hepatitis. Am J Gastroenterol 101:2731-2736

76. Granito A, Muratori L, Muratori P et al (2006) Antibodies to filamentous actin (F-actin) in type 1 autoimmune hepatitis. J Clin Pathol 59:280-284

77. Gueguen P, Dalekos G, Nousbaum JB et al (2006) Double reactivity against actin-and $\alpha$-actinin defines a severe form of autoimmune hepatitis type 1. J Clin Immunol 26:495-505

78. Renaudineau Y, Dalekos GN, Gueguen P et al (2008) Anti- $\alpha$ actinin antibodies cross-react with anti-ssDNA antibodies in active autoimmune hepatitis. Clin Rev Allergy Immunol 34: 321-325

79. Von Muhlen CA, Chan EKL, Peebles CL et al (1995) Nonmuscle myosin as target antigen for human autoantibodies in patients with hepatitis $\mathrm{C}$ virus-associated chronic liver diseases. Clin Exp Immunol 100:67-74

80. Czaja AJ, Cassani F, Cataleta M et al (1996) Frequency and significance of antibodies to actin in type 1 autoimmune hepatitis. Hepatology 24:1068-1073

81. Kuiper EM, Zondervan PE, Van Buuren HR (2010) Paris criteria are effective in diagnosis of primary biliary cirrhosis and autoimmune hepatitis overlap syndrome. Clin Gastroenterol Hepatol 8:530-534

82. Chazouillerres O, Wendum D, Serfaty L et al (1998) Primary biliary cirrhosis-autoimmune hepatitis overlap syndrome: clinical features and response to therapy. Hepatology 28:296-301

83. Williams MJ, Lawson A, Neal KR et al (2009) Autoantibodies in chronic hepatitis $\mathrm{C}$ virus infection and their association with disease profile. J Viral Hepat 16:325-331

84. Muratori P, Muratori L, Guidi M et al (2005) Clinical impact of non-organ-specific autoantibodies on the response to combined antiviral treatment in patients with hepatitis C. Clin Infect Dis 40:501-507

85. Himoto T, Tani J, Miyoshi $\mathrm{H}$ et al (2011) Efficacy of the detection for anti-F-actin antibodies by an indirect immunofluorescent method using VSM 47 cells as substrates. Dig Organ Mucosal Immunol 48:161-164 (in Japanese)

86. Zachou K, Oikonomou K, Renaudineau Y et al (2012) Anti- $\alpha$ actinin antibodies as new predictors of response to treatment in autoimmune hepatitis type 1 . Aliment Pharmacol Ther 35:116-125

87. Strassburg CP, Manns MP (2002) Autoantibodies and autoantigens in autoimmune hepatitis. Semin Liver Dis 22:339-351

88. Rizzetto M, Awana G, Doniach D (1973) Microsomal antibodies in active chronic hepatitis and other disorders. Clin Exp Immunol 15:331-344

89. Homberg JC, Abuaf N, Bernard ON (1987) Chronic active hepatitis associated with antiliver/kidney microsome antibody type 1: a second type of autoimmune hepatitis. Hepatology 7:1333-1339 
90. Durazzo M, Philipp T, Van Pelt FN et al (1995) Heterogeneity of liver-kidney microsomal autoantibodies in chronic hepatitis $\mathrm{C}$ and D virus infection. Gastroenterology 108:455-462

91. Manns MP, Griffin KJ, Sullivan K et al (1991) LKM-1 autoantibodies recognize a short liner sequence in P450IID6, a cytochrome P-450 monooxygenase. J Clin Invest 88:1370-1378

92. Dalekos GN, Wedemeyer H, Obermayer-Straub O et al (1999) Epitope mapping of cytochrome P4502D6 autoantigen in patients with chronic hepatitis $\mathrm{C}$ during alpha-interferon treatment. J Hepatol 30:366-375

93. Ma Y, Thomas MG, Okamoto M et al (2002) Key residues of a major cytochrome P4502D6 epitope are located on the surface of the molecule. J Immunol 169:277-285

94. Bogdanos DP, Lenzi M, Okamoto M et al (2004) Multiple viral/ self immunological cross-reactivities in liver kidney microsomal antibody positive hepatitis $\mathrm{C}$ virus-infected patients is associated with the possession of HLA B51. Int J Immunopathol Pharmacol 17:83-92

95. Dalekos GN, Obermayer-Straub P, Bartels M et al (2003) Cytochrome P4502A6: a new hepatic autoantigen in patients with chronic hepatitis C virus infection. J Hepatol 39:800-806

96. Bogdanos DP, Mieli-Vergani G, Vergani D (2009) Autoantibodies and their antigens in autoimmune hepatitis. Semin Liver Dis 29:241-253

97. Girardin F, Daali Y, Gex-Fabry M et al (2012) Liver kidney microsomal type 1 antibodies reduce the CYP2D6 activity in patients with chronic hepatitis $\mathrm{C}$ virus infection. J Viral Hepat 19:568-573

98. Nishioka M, Morshed SA, Kono K et al (1997) Frequency and significance of antibodies to p450IID6 protein in Japanese patients with chronic hepatitis C. J Hepatol 26:992-1000

99. Muratori L, Bogdanos DP, Muratori P et al (2005) Susceptibility to thyroid disorders in hepatitis C. Clin Gastroenterol Hepatol 3:595-603

100. Manns M, Gerken G, Kyriatsoulis A et al (1987) Characterisation of a new subgroup of autoimmune chronic active hepatitis by autoantibodies against a soluble liver antigen. Lancet I:292-294

101. Wien I, Brunner S, Henniger J et al (2000) Identification of target antigen for SLA/LP autoantibodies in autoimmune hepatitis. Lancet 355:1510-1515

102. Stechemesser E, Klein R, Berg P (1993) Characterization and clinical relevance of liver-pancreas antibodies in autoimmune hepatitis. Hepatology 18:1-9

103. Kanzler S, Weidemann C, Gerken G et al (1999) Clinical significance of autoantibodies to soluble liver antigen in autoimmune hepatitis. J Hepatol 31:635-640

104. Ballot E, Homberg JC, Johanet C (2000) Antibodies to soluble liver antigen: an additional marker in type 1 autoimmune hepatitis. J Hepatol 33:208-215

105. Cjaza AJ, Donaldoson PT, Lohse AW (2002) Antibodies to soluble liver antigen/liver pancreas and HLA risk factor for type 1 autoimmune hepatitis. American J Gastroenterol 97:413-419

106. Eyraud V, Chazouilleres O, Ballot E et al (2009) Significance of antibodies to soluble liver antigen/liver pancreas: a large French study. Liver Int 29:857-864

107. Nishioka M, Morshed SA, Parveen S et al (1997) Antibodies to p450IID6, SLA, PDH-E2and BCKD-E2 in Japanese patients with chronic hepatitis. J Gastroenterol Hepatol 12:862-868

108. Vitozzi S, Lapierre P, Djilali-Saiah I et al (2004) Anti-soluble liver antigen (SLA) antibodies in chronic HCV infection. Autoimmunity 37:217-222

109. Czaja AJ, Shums Z, Norman GL (2004) Nonstandard antibodies as prognostic markers in autoimmune hepatitis. Autoimmunity 37:195-201
110. Baeres M, Herkel J, Czaja AJ et al (2002) Establishment of standardised SLA/LP immunoassays: specificity for autoimmune hepatitis, worldwide occurrence and clinical characteristics. Gut 51:259-264

111. Van de Water J, Cooper A, Surh CD et al (1989) Detection of autoantibodies to recombinant mitochondrial proteins in patients with primary biliary cirrhosis. N Eng J Med 320:1377-1380

112. Surh CD, Coppel R, Gershwin ME (1990) Structural requirement for autoreactivity on human pyruvate dehydrogenase-E2, the major autoantigen of primary biliary cirrhosis. Implication for a conformational autoepitope. J Immunol 144:3367-3374

113. Lleo A, Invernizzi P, Mackay IR et al (2008) Etiopathogenesis of primary biliary cirrhosis. World J Gastroenterol 14:3328-3337

114. Gabeta S, Norman GL, Liaskos C et al (2007) Diagnostic relevance and clinical significance of the new enhanced performance M2 (MIT3) ELISA for the detection of IgA and IgG antimitochondrial antibodies in primary biliary cirrhosis. J Clin Immunol 27:378-387

115. Tanaka A, Nalbandian G, Van de Water J et al (2000) Mucosal immunity and primary biliary cirrhosis: presence of antimitochondrial antibodies in urine. Hepatology 32:910-915

116. Masuda J, Omagari K, Ohba K et al (2003) Correlation between histopathological findings of the liver and IgA class antibodies to 2-oxo-acid dehydrogenase complex in primary biliary cirrhosis. Dig Dis Sci 48:932-938

117. Fukushima N, Nalbandian G, Van de Water J et al (2002) Characterization of recombinant monoclonal IgA anti-PDC-E2 autoantibodies derived from patients with PBC. Hepatology 36:1383-1392

118. Matsumura S, Van de Water J, Leung P et al (2004) Caspase induction by $\operatorname{IgA}$ antimitochondrial antibody: $\operatorname{IgA}$-mediated biliary injury in primary biliary cirrhosis. Hepatology 39:1415-1422

119. Nezu S, Tanaka A, Yasui H et al (2006) Presence of antimitochondrial autoantibodies in patients with autoimmune hepatitis. J Gastroenterol Hepatol 21:1448-1454

120. Ramos-Casals M, Pares A, Jara LJ et al (2005) Antimitochondrial antibodies in patients with chronic hepatitis $\mathrm{C}$ virus infection: description of 18 cases and review of the literature. J Viral Hepat 12:648-654

121. Van Norstrand MD, Malinchoc M, Lindor KD et al (1997) Quantitative measurement of autoantibodies to recombinant mitochondrial antigens in patients with primary biliary cirrhosis: relationship of levels of autoantibodies to disease progression. Hepatology 25:6-11

122. Jin Q, Moritoki Y, Lleo A et al (2012) Comparative analysis of portal cell infiltrates in antimitochondrial autoantibody-positive versus antimitochondrial autoantibody-negative primary biliary cirrhosis. Hepatology 55:1495-1506

123. Aric L, Thebault S, Selves J et al (2007) Characterization of overlap syndrome between primary biliary cirrhosis and autoimmune hepatitis according to antimitochondrial status. Gastroenterol Clin Biol 31:11-16

124. Rigopoulou EI, Davies ET, Bogdanos DP et al (2007) Antimitochondrial antibodies of immunoglobulin G3 subclass are associated with a more severe disease course in primary biliary cirrhosis. Liver Int 27:1226-1231

125. Kawai T, Hosoya N, Moritoki Y et al (2009) Autoantibody IgG subclasses to recombinant antigens and the role of bacterial stimuli in primary biliary cirrhosis. Hepatol Res 39:874-881

126. Leung PS, Rossaro L, Davis PA et al (2007) Antimitochondrial antibodies in acute liver failure: implications for primary biliary cirrhosis. Hepatology 46:1436-1442

127. Hagen EC, Andrassy K, Csernok E et al (1993) EEC/BCR Group for ANCA assay standardization. The value of indirect 
immunofluorescence and solid phase techniques for ANCA detection. A report on the first phase of an ANCA assays. J Immunol Methods 159:1-6

128. Bansi D, Chapman R, Fleming K (1996) Antineutrophil cytoplasmic antibodies in chronic liver diseases: prevalence, titre, specificity and IgG subclass. J Hepatol 24:581-586

129. Orth T, Gerken G, Kellner R et al (1997) Actin is a target antigen of anti-neutrophil cytoplasmic antibodies (ANCA) in autoimmune hepatitis type 1. J Hepatol 26:37-47

130. Sobajima J, Ozaki S, Uesugi H et al (1999) High mobility group (HMG) non-histone chromosomal protein HMG1 and HMG2 are significant target antigens of perinuclear anti-neutrophil cytoplasmic antibodies in autoimmune hepatitis. Gut 44:867-873

131. Terjung B, Herzog V, Worman HJ et al (1998) Atypical antineutrophil cytoplasmic antibodies with perinuclear fluorescence in chronic inflammatory bowel diseases and hepatobiliary disorders colocalized with nuclear lamina proteins. Hepatology 28:332-340

132. Terjung B, Spengler U, Sauerbruch T et al (2000) Atypical p-ANCA in IBD and hepatobiliary disorders react with a 50-kilodalton nuclear envelope protein of neutrophils and myeloid cell lines. Gastroenterology 119:310-322

133. Targan SR, Landers C, Vidrich A, Czaja AJ (1995) High-titer antineutrophil cytoplasmic antibodies in type-1 autoimmune hepatitis. Gastroenterology 108:1159-1166

134. Schwarze C, Terjung B, Lilienweiss P et al (2003) IgA class antineutrophil cytoplasmic antibodies in primary sclerosing cholangitis and autoimmune hepatitis. Clin Exp Immunol 133:283-289

135. Terjung B, Spengler U (2009) Atypical p-ANCA in PSC and AIH: a hint toward a "leaky gut"? Clin Rev Allergy Immuno 36:40-51

136. Roozendaal C, de Jong MA, van den Berg AP et al (2000) Clinical significance of anti-neutrophil cytoplasmic antibodies in autoimmune liver disease. J Hepatol 32:734-741

137. Meyer zum Büschenfelde KH, Treichel U, Löhr H et al (1991) Human asialoglycoprotein receptor as an autoantigen in chronic hepatitis. Immunol Res 10:497-502

138. Treichel U, Gerken G, Rossol S et al (1993) Autoantibodies against the human asialoglycoprotein receptor: effects of therapy in autoimmune and virus-induced chronic active hepatitis. J Hepatol 19:55-63

139. Czaja AJ, Pfeifer KD, Decker RH et al (1996) Frequency and significance of antibodies to asialoglycoprotein receptor in type 1 autoimmune hepatitis. Dig Dis Sci 41:1733-1740

140. Roggenbuck D, Mytilinaiou MG, Lapin SV, Reinhold D, Conrad K (2012) Asialoglycoprotein receptor (ASGPR): a peculiar target of liver-specific autoimmunity. Autoimmun Highlights $3: 119-125$

141. Rigopoulou EI, Roggenbuck D, Smyk DS et al (2012) Asialoglycoprotein receptor (ASGPR) as target autoantigen in liver autoimmunity: lost and found. Autoimmun Reviews (Epub)

142. Hausdorf G, Roggenbuck D, Feist E et al (2009) Autoantibodies to asialoglycoprotein receptor (ASGPR) measured by a novel ELISA. Revival of a disease-activity marker in autoimmune hepatitis. Clin Chim Acta 408:19-24

143. Inamoto T, Brown WR (1991) IgG is associated with the asialoglycoprotein receptor in the human liver. Hepatology 14:1070-1075

144. McFarlane IG, Hegarty JE, McSorley CG et al (1984) Antibodies to liver-specific protein predict outcome of treatment withdrawal in autoimmune chronic active hepatitis. Lancet 2:954-956

145. Zhang JY, Megliorino R, Peng XX et al (2007) Antibody detection using tumor-associated antigen mini-array in immunodiagnosing human hepatocellular carcinoma. J Hepatol 46:107-114

146. Tan EM (2001) Autoantibodies as reporters identifying aberrant cellular mechanisms in tumorigenesis. $\mathrm{J}$ Clin Invest 108:1411-1415

147. Himoto T, Kuriyama S, Zhang JY et al (2005) Analyses of autoantibodies against tumor-associated antigens in patients with hepatocellular carcinoma. Int J Oncol 27:1079-1085

148. Himoto T, Kuriyama S, Zhang JY et al (2005) Significance of autoantibodies against insulin-like growth factor II mRNAbinding proteins in patients with hepatocellular carcinoma. Int $\mathbf{J}$ Oncol 26:311-317

149. Imai H, Nakano Y, Kiyosawa K, Tan EM (1993) Increasing titers and changing specificities of antinuclear antibodies in patients with chronic liver disease who develop hepatocellular carcinoma. Cancer 71:26-35

150. Nomura F, Sogawa K, Noda K et al (2012) Serum anti-Ku86 is a potential biomarker for early detection of hepatitis $\mathrm{C}$ virusrelated hepatocellular carcinoma. Biochem Biophys Res Commun 421:837-843

151. Kovas B, Patel A, Hershey JN et al (1997) Antibodies against p53 in sera from patients with systemic lupus erythematosus and other rheumatic diseases. Arthritis Rheum 40:980-985

152. Fenton CL, Patel A, Tuttle RM et al (2000) Autoantibodies to p53 in sera of patients with autoimmune thyroid disease. Ann Clin Lab Sci 30:179-183

153. Herkel J, Modrow JP, Bamberger S et al (2002) Prevalence of autoantibodies to the p53 protein in autoimmune hepatitis. Autoimmunity 35:493-496

154. Himoto T, Yoneyama H, Kurokohchi K et al (2012) Clinical significance of autoantibodies to $\mathrm{p} 53$ protein in patients with autoimmune liver disease. Can J Gastroenterol 26:125-129

155. Kurien BT, Hensley K, Bachmann M, Scofield RH (2006) Oxidatively modified autoantigens in autoimmune diseases. Free Radic Biol Med 41:549-556

156. Lonardo A, Adinolfi LE, Loria P et al (2004) Steatosis and hepatitis $\mathrm{C}$ virus: mechanisms and significance for hepatic and extrahepatic disease. Gastroenterology 126:586-597

157. Himoto T, Yoneyama H, Deguchi A et al (2010) Relationship between the production of autoantibodies to oxidized low-density lipoprotein and hepatic steatosis in patients with chronic hepatitis C. Exp Ther Med 1:663-668

158. Vidali M, Tripodi MF, Ivaldi A et al (2008) Interplay between oxidative stress and hepatic steatosis in the progression of chronic hepatitis C. J Hepatol 48:399-406

159. Gonzalez FJ (2005) Role of cytochrome p450 in chemical toxicity and oxidative stress: studies with CYP2E1. Mutat Res 569:101-110

160. Weltan MD, Farrell GC, Hall P et al (1998) Hepatic cytochrome p450 $2 \mathrm{E} 1$ is increased in patients with nonalcoholic steatohepatitis. Hepatology 27:128-133

161. Gochee PA, Jonsson JR, Clouston AD et al (2003) Steatosis in chronic hepatitis $\mathrm{C}$ : association with increased messenger RNA expression of collagen I, tumor necrosis factor- $\alpha$ and cytochrome p450 2E1. J Gastroenterol Hepatol 18:386-392

162. Tsutsumi M, Lasker JM, Shimizu M et al (1989) The intralobular distribution of ethanol-inducible p450IIE1 in rat and human liver. Hepatology 10:437-446

163. Vidali M, Occhino G, Ivaldi A et al (2007) Detection of autoantibodies against cytochrome p450 (CYP2E1) in chronic hepatitis C. J Hepatol 46:605-612

164. Sutti S, Vidali M, Mombello C et al (2010) Breaking self-tolerance toward cytochrome p4502E1 (CYP2E1) in chronic hepatitis C: possible role for molecular mimicry. J Hepatol $53: 431-438$ 
165. Njoku DB, Mellerson JL, Talor MV et al (2006) Role of CYP2E1 immunoglobulin G4 subclass antibodies and complement in pathogenesis of idiosyncratic drug-induced hepatitis. Clin Vaccine Immunol 13:258-265

166. Liaskos C, Rigopoulou E, Zachou K et al (2005) Prevalence and clinical significance of anticardiolipin antibodies in patients with type 1 autoimmune hepatitis. J Autoimmun 24:251-260

167. Zachou K, Liaskos C, Rigopoulou E et al (2006) Presence of high avidity anticardiolipin antibodies in patients with autoimmune cholestatic liver diseases. Clin Immunol 119:203-212

168. Harada M, Fujisawa Y, Sakisaka S et al (2000) High prevalence of anticardiolipin antibodies in hepatitis $\mathrm{C}$ virus infection: lack of effects on thrombocytopenia and thrombotic complications. J Gastroenterol 35:272-277

169. Himoto T, Yoneyama H, Kurokohchi K et al (2012) Clinical relevance of antibodies to cardiolipin in patients with chronic hepatitis C. J Clin Lab Anal 26:342-348

170. Nagao Y, Tsubone K, Kimura R et al (2002) High prevalence of anticardiolipin antibodies in patients with $\mathrm{HCV}$-associated oral lichen planus. Int J Mol Med 9:293-297

171. Miyata M, Kogure A, Sato H et al (1995) Detection of antibodies to $65 \mathrm{kD}$ heat shock protein and to human superoxide dismutase in autoimmune hepatitis-molecular mimicry between $65 \mathrm{kD}$ heat shock protein and superoxide dismutase. Clin Rheumatol 14:673-677

172. Chumpitazi BF, Bouillet L, Drouet MT et al (2008) Biological autoimmunity screening in hepatitis $\mathrm{C}$ patients by anti-HEpG2 lysate and anti-heat shock protein 70.1 autoantibodies. Eur J Clin Infect Dis 28:137-146

173. Chan WB, Chow CC, Cockram CS (2003) Interferon alpha treatment and endocrine disease. J R Soc Med 96:481-485

174. Himoto H, Masaki T (2012) Extrahepatic manifestations and autoantibodies in patients with hepatitis $\mathrm{C}$ virus infection. Clin Dev Immunol (Epub)

175. Deutsch M, Dourakis S, Manesis EK et al (1997) Thyroid abnormalities in chronic viral hepatitis and their relationship to interferon alpha therapy. Hepatology 26:206-210
176. Piquer S, Hernandez C, Enriquez J et al (2001) Islet cell and thyroid antibody prevalence in patients with hepatitis $\mathrm{C}$ virus infection: effect of treatment with interferon. J Clin Med 137:38-42

177. Fabris P, Betterle C, Greggio NA et al (1998) Insulin-dependent diabetes mellitus during alpha-interferon therapy for viral hepatitis. J Hepatol 28:514-517

178. Kakizaki S, Takagi H, Murakami M et al (1999) HLA antigens in patients with interferon-a-induced autoimmune thyroid disorders in chronic hepatitis C. J Hepatol 30:794-800

179. Martocchia A, Labbadia G, Paoletti V et al (2001) Hashimoto's disease during interferon-alpha therapy in patients with pretreatment negative anti-thyroid autoantibodies and with the specific genetic susceptibility to the thyroid disease. Neuro Endocrinol Lett 22:49-52

180. Parana R, Schinori MI, de Freitas LA et al (2006) Anti-Golgi complex antibodies during pegylated-interferon therapy for hepatitis C. Liver Int 26:1148-1154

181. Covini G, Carcamo WC, Bredi E, et al (2012) Cytoplasmic rods and ring autoantibodies developed during pegylated interferon and ribavirin therapy in patients chronic hepatitis C. Antivir Ther (Epub)

182. Carcamo WC, Ceribelli A, Calise SJ, et al (2012) Differential reactivities to IMPHD2 by anti-rods/rings autoantibodies and unresponsiveness to pegylated interferon-alpha/ribavirin therapy in US and Italian HCV patients. J Clin Immunol (Epub)

183. Vaquez-Del Mercado M, Sanchez-Orozco LV, Pauley BA et al (2010) Autoantibodies to a miRNA-binding protein Argonaute 2 (Su antigen) in patients with hepatitis $\mathrm{C}$ virus infection. Clin Exp Rheumatol 28:842-848

184. Gatselis NK, Georgiadou SP, Koukoulis GK et al (2006) Clinical significance of organ- and non-organ-specific autoantibodies on the response to anti-viral treatment of patients with chronic hepatitis C. Aliment Pharmacol Ther 24:1563-1573

185. Tomer Y (2010) Hepatitis $C$ and interferon induced thyroiditis. J Autoimmun 34:J322-J326 